\title{
TITLE:
}

\section{TWO NEW ACROTHORACICAN CIRRIPEDS FROM JAPAN}

$\operatorname{AUTHOR}(\mathrm{S})$ :

Tomlinson, Jack T.

\section{CITATION:}

Tomlinson, Jack T.. TWO NEW ACROTHORACICAN CIRRIPEDS FROM JAPAN. PUBLICATIONS OF THE SETO MARINE BIOLOGICAL LABORATORY 1963, 11(2): 263-280

ISSUE DATE:

1963-12-31

URL:

http://hdl.handle.net/2433/175342

RIGHT: 


\title{
TWO NEW ACROTHORACICAN CIRRIPEDS FROM JAPAN ${ }^{13}$
}

\author{
JACK T. TOMLINSON \\ School of Biology \\ San Francisco State College
}

With 18 Text-figures

During work being conducted at the Seto Marine Biological Laboratory on the sexual mechanisms of the Acrothoracica, two new species of these burrowing barnacles were discovered. One of them is remarkable, for it is the first to possess a full complement of appendages. Not only does this discovery remove an important obstacle to the recognition of the Acrothoracica as having fundamentally the same details of structure as the common barnacles or Thoracica, but it puts an end to at least one controversy regarding the homology of the appendages in these two groups.

All of the Acrothoracica known previously to this report, no doubt in response to their very special way of life, have lost one or more pairs of appendages over the theoretical full complement: the number and kinds seen in the Thoracica and Ascothoracica. The Thoracica have, fundamentally, six pairs of cirri and one pair of caudal appendages. In the least modified acrothoracicans there are six pairs of cirri and no caudal appendages, or five pairs of cirri and one pair of caudal appendages. The question has been, are the so-called caudal appendages of Acrothoracica, homologous to the caudal appendages of the Thoracica, or are they rudiments of a reduced pair of cirri? This question is answered here, for one of the new Japanese species has the full number of cirri : six; and in addition has a well-developed pair of caudal appendages. A new genus and family is proposed for this new form, which presently includes the least modified acrothoracican.

The systematics of the Order Acrothoracica is poorly understood, in part, because relatively few species have been described. It is not agreed what characteristics are of taxonomic importance, and a number of characters in use are variable. Considerable importance has been placed on the presence or absence of an attachment disc, yet the evidence for its presence or absence is often conjectural. The details of the lip of the mantle aperture vary as the

1) Contributions from the Seto Marine Biological Laboratory, No. 403.

Publ. Seto Mar. Biol. Lab., XI (2), 1963. (Article 16) 
animal matures, and the details of the mandible and other mouth parts vary as much within a species as between certain genera. The presence of various body processes varies within a genus, and their presence or absence may be very difficult to determine. The musculature may prove to be useful in taxonomic studies, but to date only UTiNom $(1960,1961,1963)$ has been thorough in this aspect. Descriptions based on dried specimens can be accurate for chitinous structures, but may be unreliable with regard to soft structure such as musculature. There is a problem in determining the number of segments in the mouth cirri and the caudal appendages. These are reduced structures, being lost completely in some species, and the segmentation is often not distinct: wrinkles and folds in the integument can be very confusing, but where sufficient material is available, one may at least give the range of variation, or indicate any difficulties observed in making the counts. It is quite likely that some previously published species descriptions imply a confidence in the segment counts which will prove misleading.

Unless otherwise stated, all descriptions pertain to the female.

ORDER ACROTHORACICA GRUVEL 1905 (Emend)

Burrowing cirripeds with soft carapace, without calcareous plates; cirri usually reduced, $3-5$ pairs concentrated toward posterior end of body; one pair of cirri usually present in vicinity of mouth; with or without caudal appendages. Three pairs of mouth appendages: mandible with palp, first and second maxillae. Abdomen lacking in adult. Males dwarf and much reduced in structure; ovaries contained in a more or less flattened part of mantle, the same forming point of attachment in attached forms. Development always includes a cyprid stages, free nauplii frequently deleted. Live buried in barnacle, chiton, gastropod, and pelecypod shells, and in corals and lime stone. Fossil forms in lime stone, corals, echinoids, and many mollusk shells ; Carboniferous to Recent.

Suborder Pygophora BERnd 1907

Acrothoracica with terminal cirri biramous; brain with 2 ventral ganglia; alimentary canal complete; caudal appendage may be present or absent.

Family Utinomiddae fam. nov.

Pygophora with one pair of biramous mouth cirri; 5 pairs of biramous terminal cirri; caudal appendages present.

\section{Utinomia gen. nov.}

Monotypic family. Mantle with attachment disc; aperture with numerous small teeth on a heavily-chitinized apertural margin, without hooks or spines. Anterior and posterior rami of mouth cirrus biramous, with 5 and 4 (or 4 and 3 , or completely obscure) segments respectively; supported by a 2 -segmented pedicle. 
The genus is named in honor of the eminent cirripedologist, Prof. Huzio Uтіломi, of the Seto Marine Biological Laboratory.

Utinomia newmani sp. nov. (figs. 1-6)

Monotypic genus.

Type material: Seto Marine Biological Laboratory Holotype No. 196; San Francisco State College No. 630924.

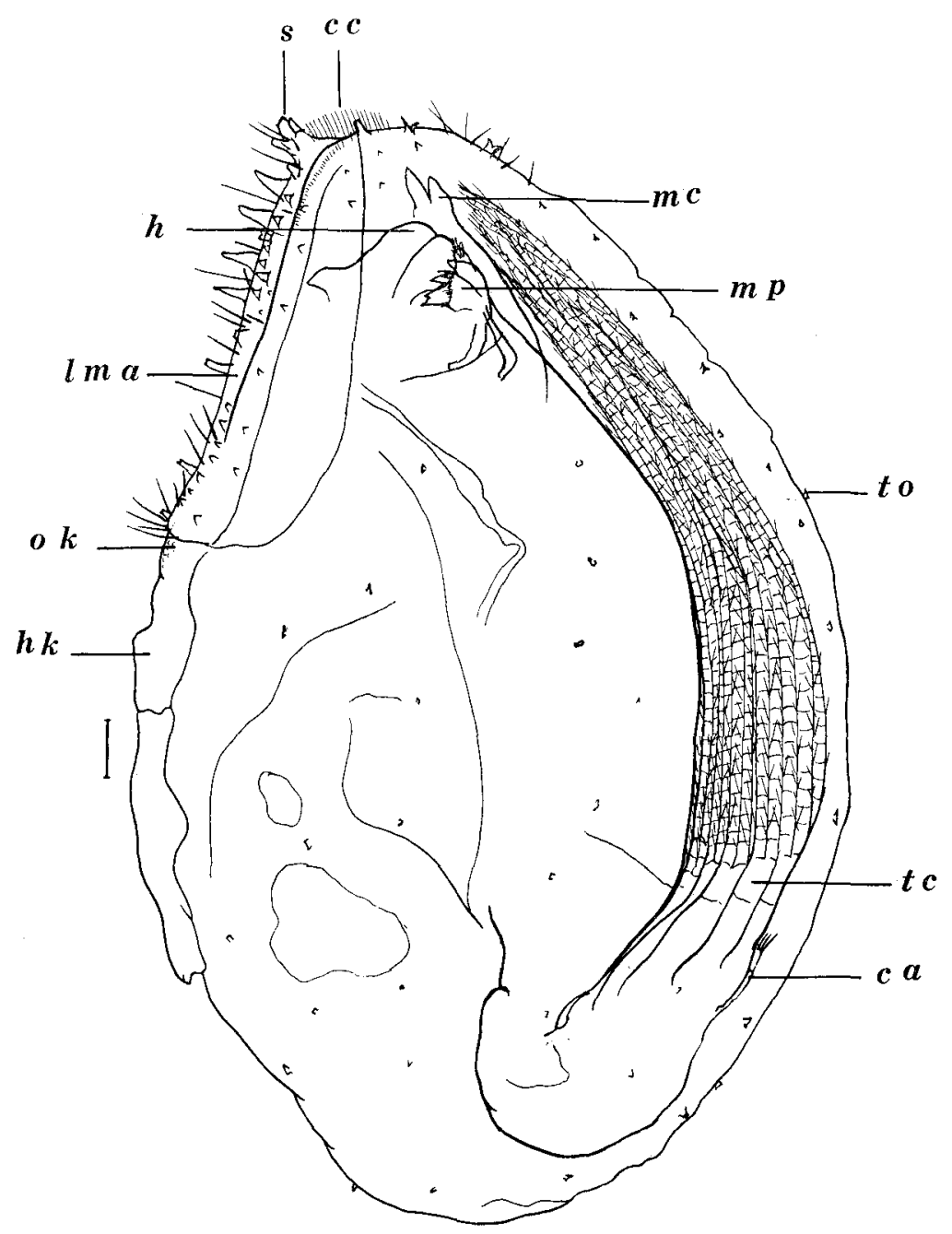

Fig. 1. Utinomia newmani, new genus, new species, holotype female. $c a$-caudal appendage ; $c c-$ comb collar ; $h$-head ; $h k$-horny knob ; lma-lip of mantle aperture ; $m c$-mouth cirrus ; $m p-$ mouth parts; $o k$-orificial knob; $s$-spine; $t c$-terminal cirrus ; to-tooth. All scales $0.1 \mathrm{~mm}$. 
Four dried specimens in Bursa bufo (RöDING) from area of Seto, Wakayamaken, Japan.

The size of the type specimen is $2.0 \times 1.2 \mathrm{~mm}$ in length and width.

The four specimens were found in one Bursa bufo shell, with three dried specimens of the species of Kochlorine also described in this paper. This is the first time that two species of Acrothoracica have been reported from a single shell, or even the same species of shell. In that two species occupying

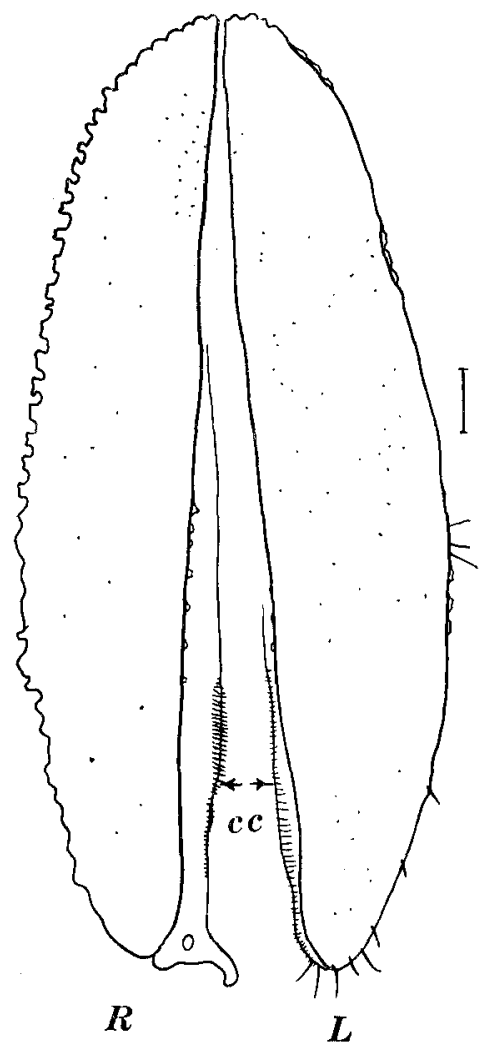

Fig. 2. Utinomia newmani, female. Lip of mantle aperture. $c c$ - comb collar ; $L$-left side ; $R$-right side. Scale $0.1 \mathrm{~mm}$.

the shell were not expected, and Acrothoracica are best removed by decalcifying the substratum containing them, the exact dimensions of the burrow of this species cannot be given. All burrows in the shell appeared typical for acrothoracicans (exclusive of the family Trypetesidae), that is, a tapered slit more pointed on one end, resembling the upper part of an exclamation mark ( $c f$. fig. 18). Three of the four specimens were dissected completely. The remaining specimen, the one considered to be in the best condition, was selected as the holotype (fig. 1). 
The mantle appears to be nearly devoid of musculature; although the apparent lack of musculature is perhaps due to the dried condition, the other species from the same shell has musculature readily visible. The attachment area is very narrow, yet a small strip of horny cemented exuviae can be seen. Very small single and bifurcated teeth are scattered across the entire mantle surface.

The lips of the mantle aperture are a bright vermillion, in the dried state. They are well developed, and bear heavy single teeth on their outer margin (fig. 2). In all specimens these teeth had been badly broken, or worn down, so their actual length is unknown. Many very small teeth and long bristles are scattered over the external surface of these lips. The inner edges

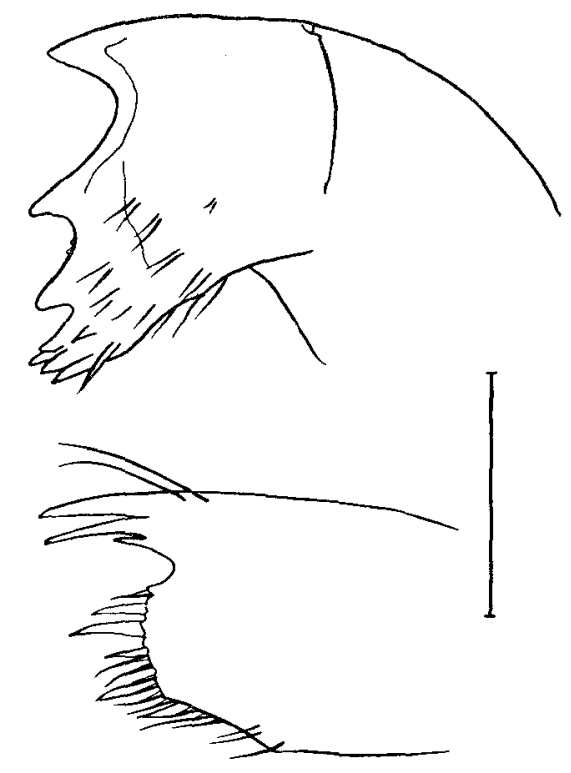

Fig. 3. Utinomia newmani, female. Mandible (top) and first maxilla. Scale $0.1 \mathrm{~mm}$.

of the lips bear the typical "comb-collars": membranes with many fine folds with free crenulated edges, giving the appearance of a row of very ordered bristles. The hook-like structure between the lips in figure 2 is a fragment of the torn comb-collar.

The orificial knob (fig. 1) at the posterior end of the aperture is reduced to a low tubercle covered with very fine papillae. The "horny knob" is very flat. The aperture is $0.88 \mathrm{~mm}$ long, measured as a straight line cutting across the mantle just over the prosoma.

The mouth parts (fig. 3), consisting of the mandibles with palps and two pairs of maxillae, are typical for the group. The palps and second maxillae (not illustrated, $c f$. fig. 9C) are very similar to those of other species. 
The mandible (fig. 3) bears three major teeth, which diminish in size slightly toward the inner or inferior angle; inferior angle with cluster of four or more teeth with subsidiary teeth on the sides.

The first maxillae (fig. 3) have two major and a minor tooth on the upper or superior angle, a conspicuous notch without armature, and a cluster of three to five thinner teeth set among bristles of varying sizes along the lower cutting edge.

Segmentation of the mouth cirri tends to be obscure or vestigial, making

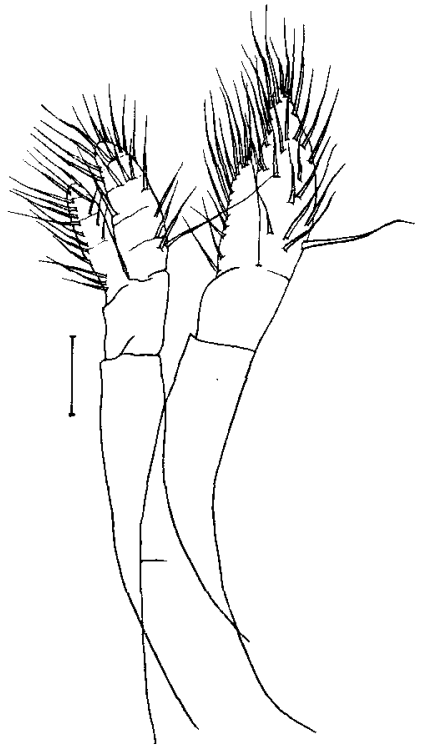

Fig. 4. Utinomia newmani, female. Mouth cirri. Scale $0.1 \mathrm{~mm}$

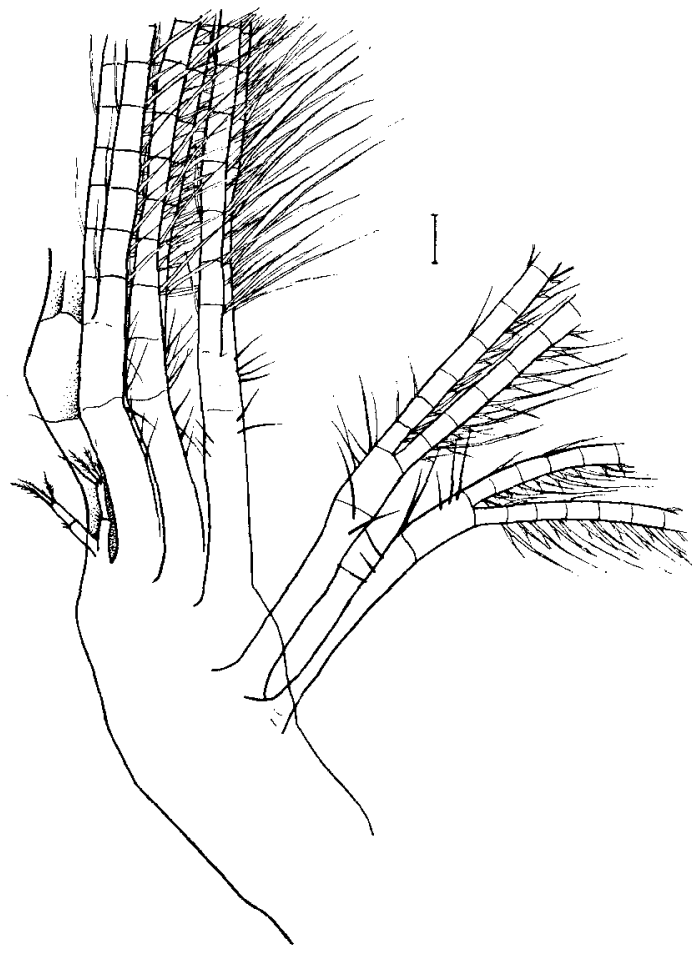

Fig. 5. Utinomia newmani, female. Terminal cirri and caudal appendages. Shaded cirrus is one of the last (fifth) pair of terminal cirri. Scale $0.1 \mathrm{~mm}$.

it difficult to describe. Two cirri from one specimen are illustrated (fig. 4), showing 5 and 4 segments in the anterior and posterior rami of one cirrus, and none in the other. Another specimen had 4 and 3 segments, respectively. The pedicle is 2 -segmented.

There are five pairs of biramous, multi-segmented terminal cirri. The setation is typical for the suborder. The lesser curvature of each segment supports a distal pair of long setae and a central, shorter pair. The distal 
end of every second to fifth segment along the greater curvature supports a single seta (fig. 5). The pedicles are 2 -segmented, the same vermillion color as the mantle aperture, and the proximal segment is about twice as long as the distal segment, the suture between them being perpendicular to the long axis of the cirrus.

The caudal appendages arise between and behind the last terminal cirri, being about half the height of the basal segment of the last terminal cirrus. They are uniramous and 2 -segmented, supporting 3 or 4 pinnate terminal bristles.

The male:

One male was observed. It resembles a degenerate sac with antennules

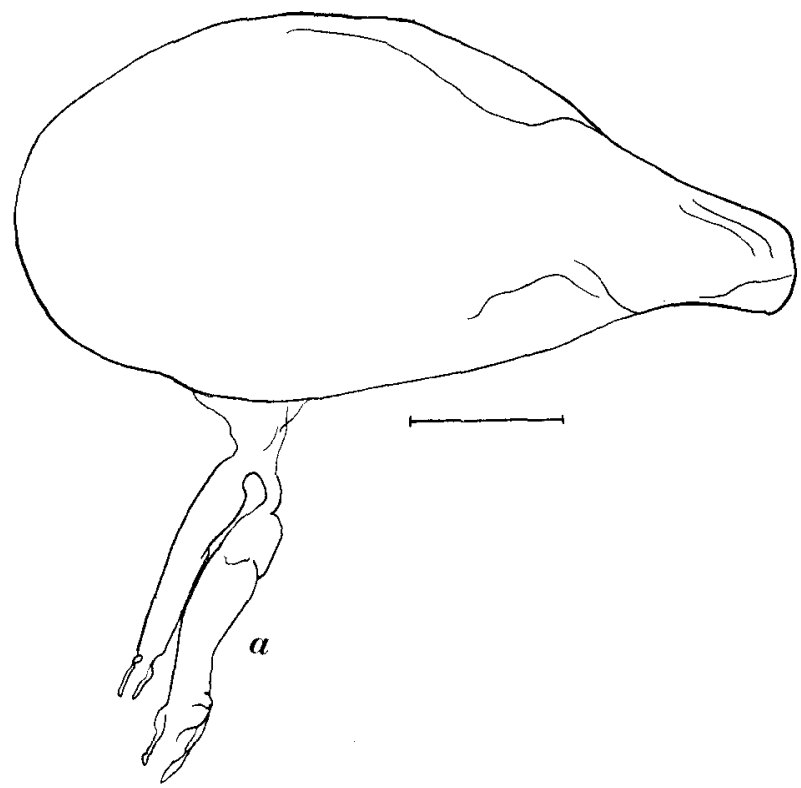

Fig. 6. Utinomia newmani, male. a-antennules. Scale $0.1 \mathrm{~mm}$.

for attachment typical for the order (fig. 6). No internal anatomy could be seen. The antennules were close to the cyprid-shaped body, not supported by a long stalk.

The species is named in honor of Dr. William A. Newman, of the Museum of Comparative Zoology, Harvard University; colleague and friend.

Affinities:

The Utinomiidae is probably closely related to the Lithoglyptidae, particularly Lithoglyptes indicus AUrIvillius. The heavily chitinized apertural lips without horns or major spines or cones, the numerous terminal cirri plus caudal appendage, and the similar mouth cirrus segmentation, indicates the similarities between these two species. Five rather than four pairs of terminal cirri 
separate the new from from the species of Lithoglyptes, and the presence of caudal appendages separates it from Berndtia and Weltneria.

Family Kochlorinidae Gruvel 1905

Kochlorinidae GRUVEL, 1905, p. 328, 335

Kochlorinidae BERNDT, 1907, p. 287

Kochlorinidae CaLmaN, 1909 , p. 140

Kochlorinidae BARNARD, 1924, p. 99

Kochlorinidae KRÜGER, 1940, p. 111, 454

Balanodytidae UTINomI, 1950a, p. 99

Balanodytidae UTINOMI, 1950b, p. 458

Kochlorinidae UTiNomI, 1963, p. 71

Pygophora with one pair of biramous mouth cirri, with short rami jointed or unjointed ; 3 or 4 pairs of terminal cirri; caudal appendages present or absent. Mantle-sac oval and laterally compresed. Mantle orifice broadly arched, slitlike, with prominent spiniferous projection(s) on each side. Attachment-disc weakly developed or reduced. Rudimentary lateral bar may be present inside of mantle. A strong retractor muscle ('retractor pallii rostralis' of UTINOMI) runs downward from attachment process.

Kochlorine Nol. 1875 Emend.

Mouth cirri biramous, may be weakly segmented; 3 pairs of thoracic cirri ; 1 pair of 2 -jointed caudal appendages; no lateral bar; (original diagnosis: mouth cirrus rami unsegmented).

Kochlorine habei sp. nov. (figs. 7-18)

Type material: Seto Marine Biological Laboratory Holotype No. 197; San Francisco State College No. 630926. Holotype $2.6 \times 1.4 \mathrm{~mm}$ in length and width.

Twelve dried specimens in Kelletia lischkei Kuroda from Tomioka, Amakusa, Kyushu, on rock $10 \mathrm{~m}$ below the surface; 3 dried specimens in Bursa bufo (RöbIvG) from the area of Seto, Wakayama-ken, Japan (in association with Utinomia newmani); 3 dried specimens in Charonia sauliae (REEve) from the area of Seto, Wakayama-ken, Japan.

Mouth cirrus (figs. 10, 15) with the anterior and posterior rami very weakly segmented, with 5 (or 4) and 4 segments seen indistinctly in some specimens; 3 pairs of terminal cirri and 1 pair of caudal appendages (fig. 11). Lip of mantle aperture with a pair of toothed hooks near the apex but not at the extreme anterior end of the aperture, with heavy single and bifurcated teeth on apertural lip (fig. 8).

Named in honor of Dr. Tadashige HABE of the National Science Museum, Tokyo, who discovered the slits in the Kelletia shells, and was so kind as to present the material to me.

The species was found in three host shells. The 12 specimens in Kelletia lischkei were better preserved than the three in Charonia sauliae and the three 
in Bursa bufo, so they will be considered the type specimens. Small differences will be discussed later. All specimens were dried, so some were softened with $\mathrm{KOH}$ for dissection of parts. The holotype is a large female $(2.6 \times 1.4 \mathrm{~mm})$, but somewhat twisted, so could not be figured accurately. A much smaller specimen $(1.6 \times 0.9 \mathrm{~mm})$ was figured (fig. 7), and is designated a paratype. The average of the seven complete specimens from Kelletia is $2.53 \times 128 \mathrm{~mm}$ in

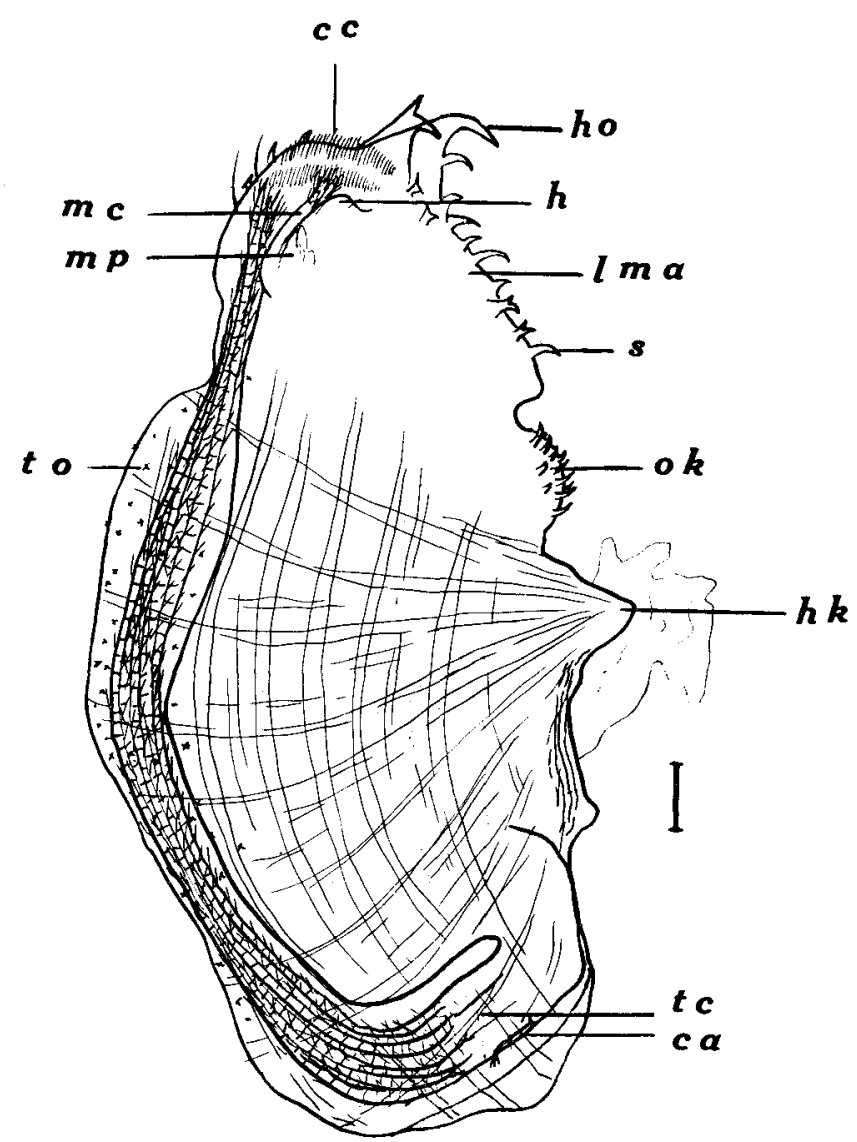

Fig. 7. Kochlorine habei, new species, paratype female. Lettering as in Figure 1. Detail of mantle aperture given for only one side. ho-hook. All scales $0.1 \mathrm{~mm}$.

greatest length and greatest mid-body width.

The colorless mantle is provided with bands of striated muscle radiating outward from the attachment knob and around the mantle from the bottom of the sack, with the former external. The area of the aperture is devoid of these bands. The mantle supports numerous extremely small, complex, starshaped teeth with 2 to 5 rays, along the edge occupied by the terminal cirri. 
An extremely heavy, multi-layered, chitinous disc covers the postero-dorsal side, where the body is attached to the mantle. This no doubt represents cemented layers of integument where it comes into contact with the attachment area. Once the animals have been removed by decalcification of the shells in which they occur, these layers can be stripped off. It is quite clear that this species cements itself into the burrow, particularly around the horny knob where the muscles originate.

The lips of the mantle aperture are heavily armed with teeth and hooks (fig. 8). Dominating the apical, or nearly anterior, end of the aperture, a pair

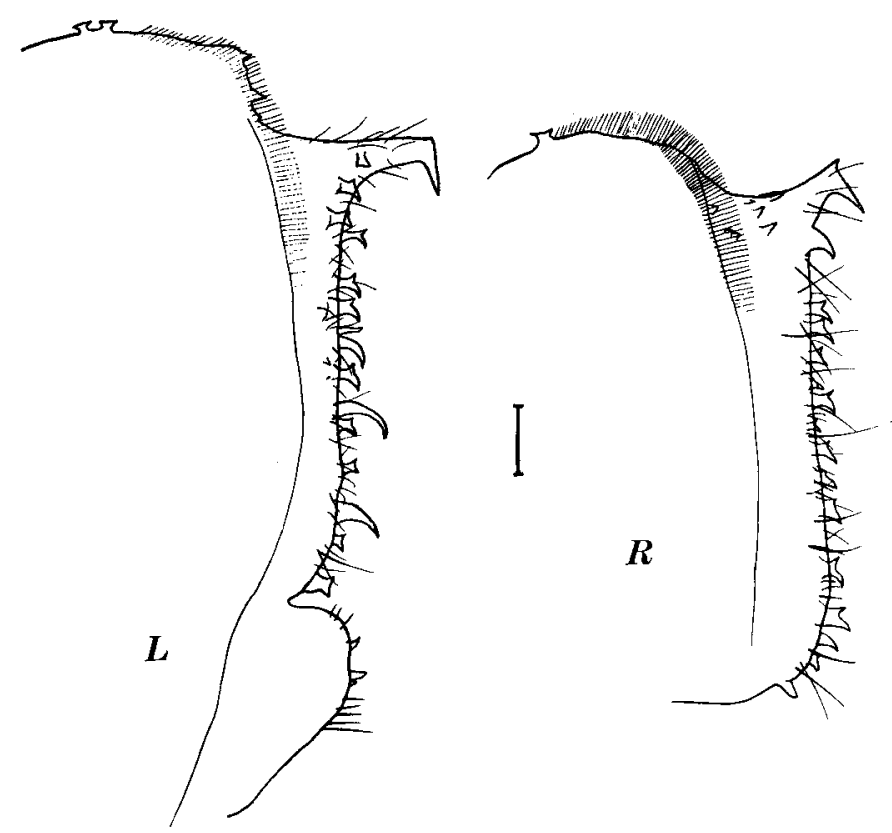

Fig. 8. Kochlorine habei, female. Lips of mantle aperture. $L-$ left side ; $R$-right side. Scale $0.1 \mathrm{~mm}$. Figures 8 to 10 are from specimens from Kelletia lischkei, but not the paratype.

of strong hooks bearing one or two strong teeth point dorsally and posteriorly. The rest of the heavily chitinized lip of the mantle aperture bears an array of heavy teeth, many single and curving postero-dorsally, but many bifurcated. A few bristles and the usual comb collar also are present on the lips. At the posterior end of the aperture the typical orificial knob is prominent, supporting many anteriorly-projecting curved teeth. The apertural length of six specimens averages $0.88 \mathrm{~mm}$.

The mouth parts (fig. 9): The mandibles with palps and two pairs of maxillae are typical for the group. Each mandible has numerous teeth grading 
downward posteriorly from large to small. Two very prominent teeth are seen, followed by at least seven smaller teeth set close together.

The first maxilla bears one to three long, curved spines on the superior angle, a broad notch, followed by two or more spines and many small setae on the lower portion of the cutting edge and inferior margin. The number of major spines of the first maxillae are not always the same in the same animal. Perhaps this is, in part, a maturational feature, much like variations in apertural armament, and therefore should be used with caution in the comparison of species.

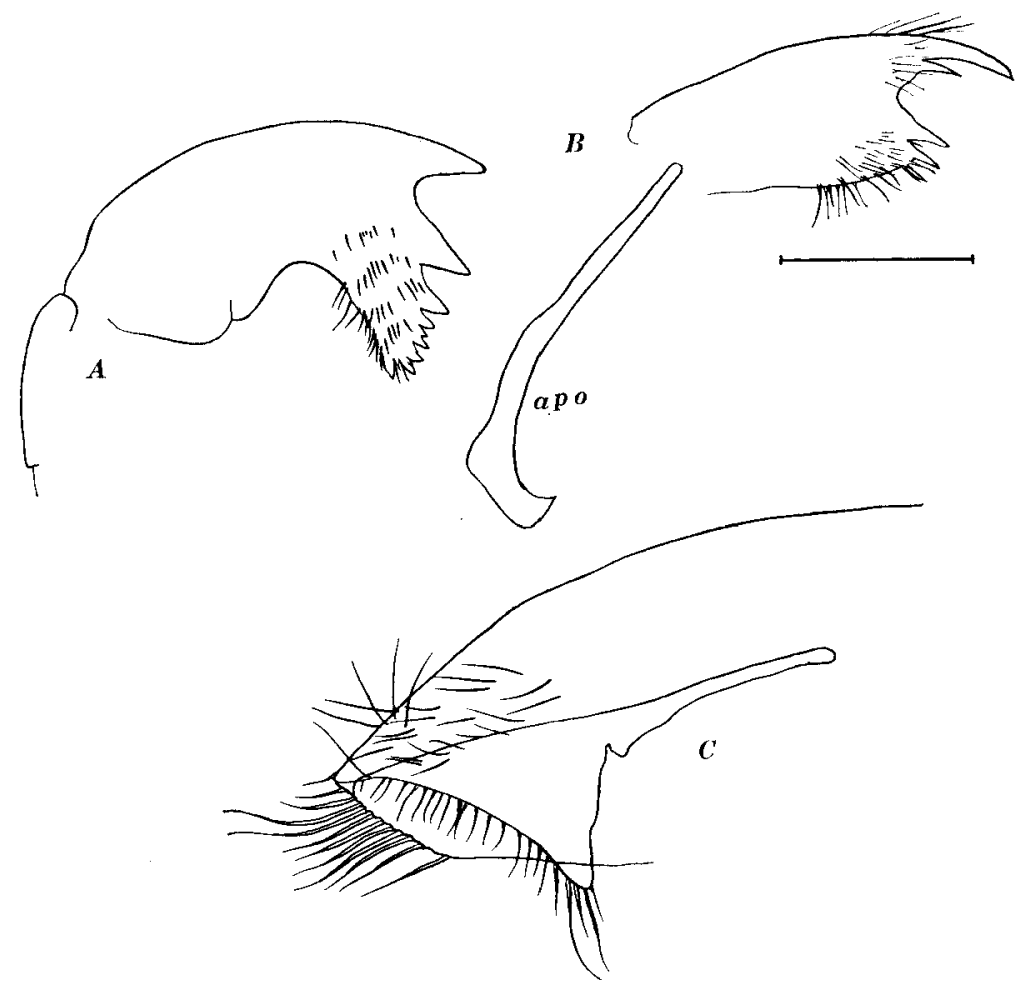

Fig. 9. Kochlorine habei, female. Mouth parts. $A$-mandible ; $B$-first maxilla ; $C$-second maxilla ; $a p o$-apodeme. Scale $0.1 \mathrm{~mm}$.

The second maxilla, a large appendage covering the mouth field from behind, bears many bristles along the anterior margin and along the fold that extends in between the other mouth parts.

The segmentation of the mouth cirrus is difficult to determine, and could not be satisfactorily illustrated. The specimens illustrated (figs. 10 and 15) show no segmentation, in accord with the original generic diagnosis. However, other specimens show what appears to be 5 (or 4) and 4 segments in the 
anterior and posterior rami, respectively, or even appear segmented in one cirrus and not in the other. The number of segments in the pedicle is dubious. Noll (1875) described a 3 -segmented pedicle, but this is doubtful from a comparative point of view, and cannot be ascertained with confidence in this material. Undoubtedly fresh specimens would help in clearing this difficulty, but again the caution that emphasis should be reduced in this characteristic is in order. The fact that segmentation of the rami can be detected in some

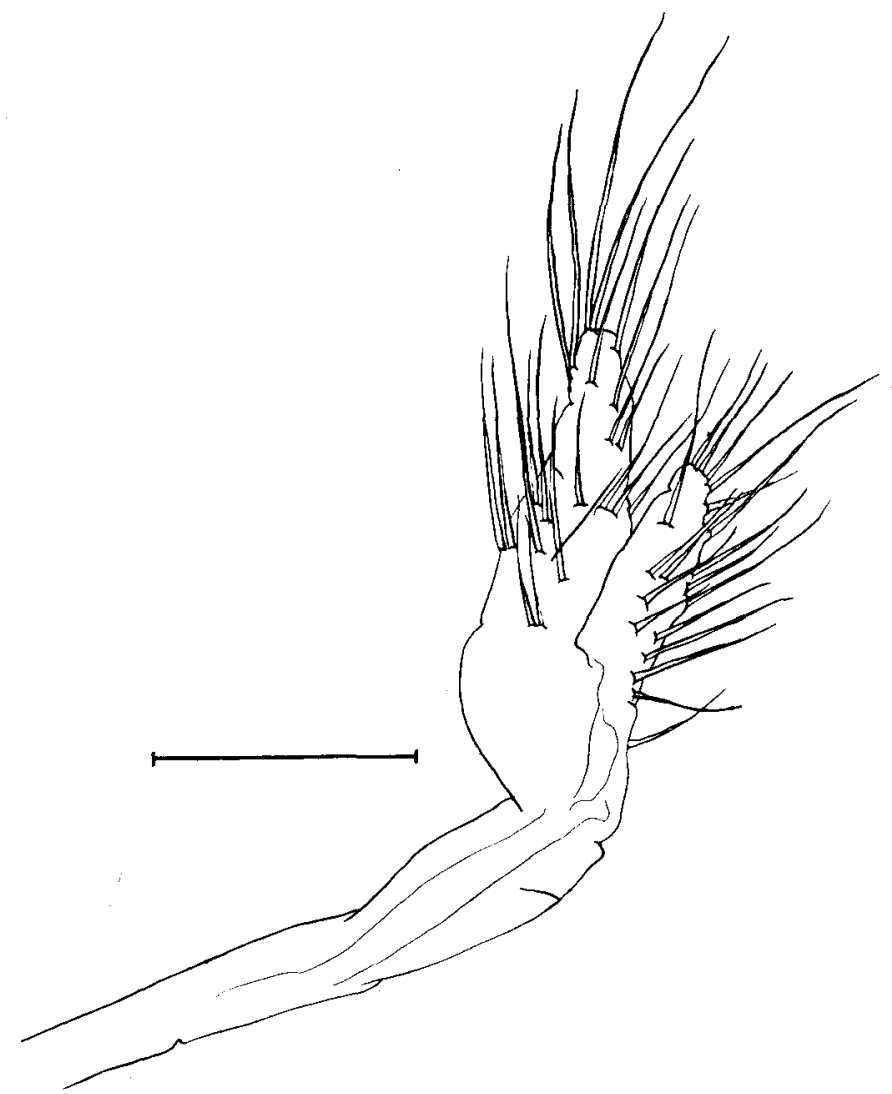

Fig. 10. Kochlorine habei, female. Mouth cirrus. Scale $0.1 \mathrm{~mm}$.

specimens which otherwise fit the genus exactly is sufficient to emend the diagnosis for the genus.

The three pairs of terminal cirri are biramous and multi-segmented. The arrangement of setae is typical for the suborder: a repetition of the distal long pair of setae and a central shorter pair on the lesser curvature of each segment, with a single seta on every second to fifth article along the greater curvature. The pedicles are 2 -segmented, with the proximal segment much longer than the distal segment. The sutures between the segments slant 
obliquely (fig. 11), much as in Lithoglyptes. The number of segments in the rami range from 18 to 43 (counts for one specimen), and increasing posteriorly.

The caudal appendages (fig. 11), arising between and behind the last pair of terminal cirri, are uniramous and 2 -segmented, with usually three pinnate terminal setae. The distal segment is markedly thinner than the basal segment, leaving a very distinct suture. The appendage itself is about half the length of the basal segment of the pedicle on the last terminal cirrus.

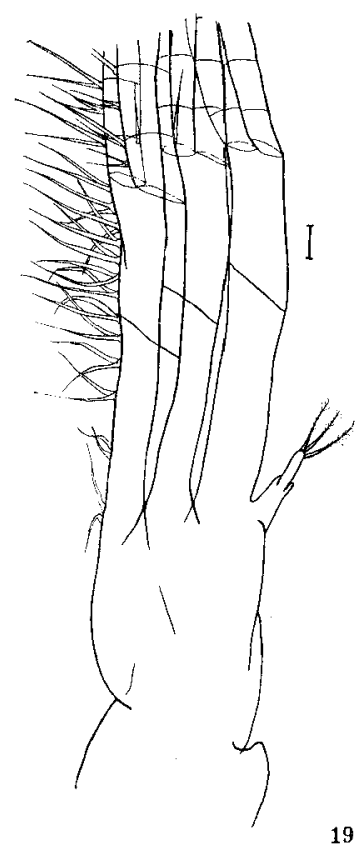

Fig. 11. Kochlorine habei, female. Terminal cirri and caudal appendage. Details for only one cirrus given ; the rest are similar. This specimen from Bursa bufo. Scale $0.1 \mathrm{~mm}$.

The male:

The degenerate male appears as a small simple sac with antennules for attachment. A stalk connecting the bulk of the body to the antennules, first described in Lthoglyptes spinatus TomLinson and Newman (1960), is present in this species. It is about as long as the bulbous part of the body (fig. 12).

The presence of a penis could not be determined in two specimens. This may be because the specimens had been dried, but there is nothing like the very obvious penis I have seen in Trypetesa lampas and Cryptophialus melampygos. A very obvious naupliar eye is present, and there is a yellowish-tan structure of unknown function appended to the body near the stalk. The latter is 
probably the "yellow organ" of UTinomi (1961). The body has a pronounced bifurcation, with the stalk attaching near the base of the fork.

The burrow:

The usual shape of acrothoracican burrows is a tapered slit, about the size

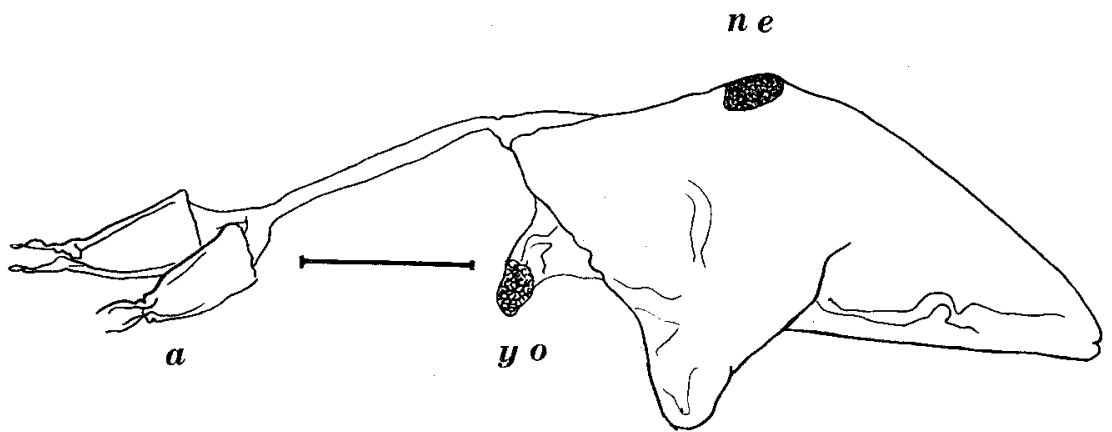

Fig. 12. Kochlorine habei. male, from Kelletia lischkei. a-antennules; ne-naupliar eye ; yo-yellow organ. Scale $0.1 \mathrm{~mm}$.

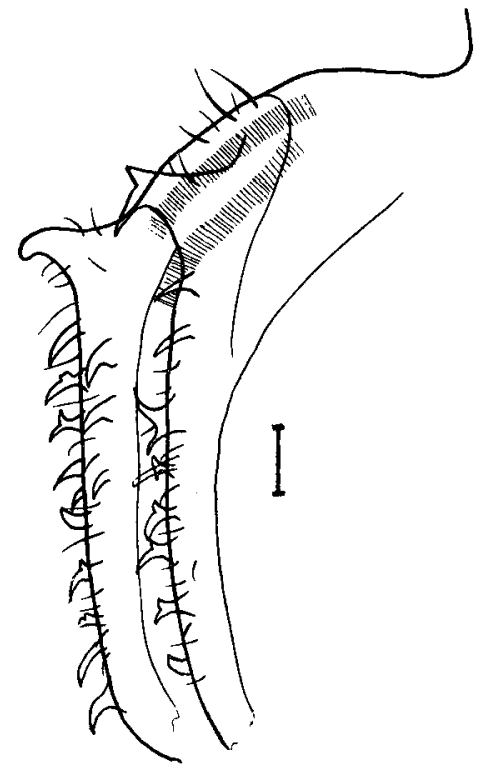

Fig. 13. Kochlorine habei, female. Lip of mantle aperture of specimen from Bursa bufo. Scale $0.1 \mathrm{~mm}$.

and shape of the top half of a typed exclamation mark. A problem in figuring or measuring these slits is that a numbr of distortions may affect the burrow: The position on the shell, presence of other organisms including algae, age 
of the barnacle, and treatment of the shell. The illustration (fig. 18) is of a single slit $(11 \times 0.23 \mathrm{~mm})$ in Charonia. In all cases the burrow is about as long as the long diameter of the mantle, but this is not perpendicular to the shell surface. The toothed, straight portion of the mantle lip fills the burrow aperture, and is parallel to the surface of the shell. The attachment knob is only a little way beneath the surface. The body may be tucked back from the pointed end of the slit about as far again as the slit is long. Again, this varies a great deal with the conditions listed above, especially the position of the burrow on the shell.

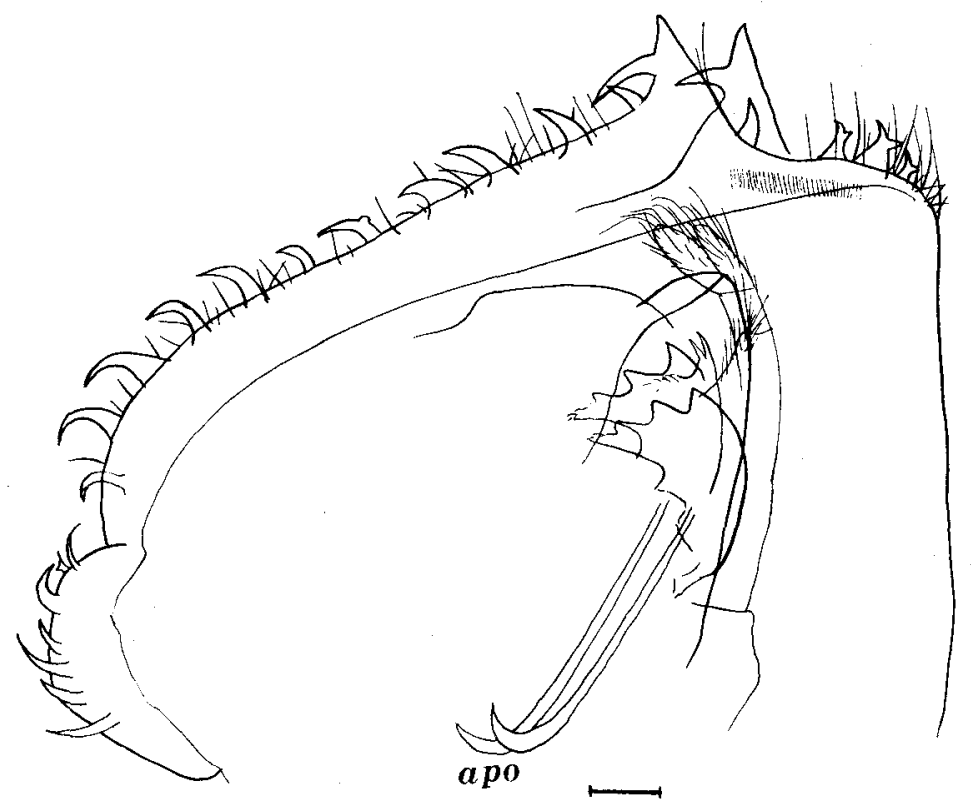

Fig. 14. Kochlorine habei, female. Aperture and head region of specimen from Charonia sauliae. Details only on one side. apoapodemes. Scale $0.1 \mathrm{~mm}$.

\section{Variations :}

Differences in the specimens from the other host shells were noted. The burrows were scattered over the shell in Kelletia and Bursa, but in Charonia the specimens were all in the apical two inches, where, although only three specimens were recovered, there were six slits.

The mouth parts differ somewhat in specimens from different hosts, but, as has been mentioned, such differences are frequently seen in the paired structures from one specimen, or different specimens from the same host shell (figs. 16 and 17). The mandible of a specimen from Bursa showed three major teeth and up to nine weak teeth, while a specimen from Charonia had the 
typical two large and a weak third tooth, and 5 to 7 smaller spines, these spines being more variable in size than those seen in specimens from Kelletia.

The first maxillae were variable. In specimens from Bursa and Charonia they had two long curved major spines plus an associated smaller one. They

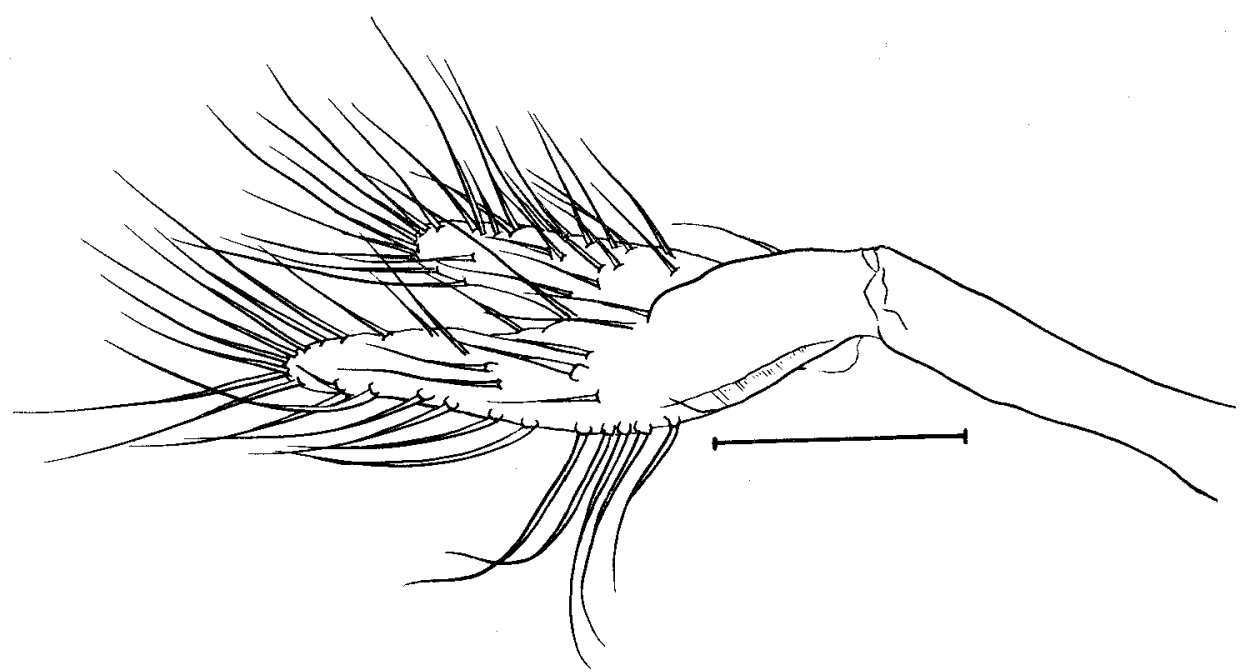

Fig. 15. Kochlorine habei, female. Mouth cirrus of specimen from Bursa bufo. Scale $0.1 \mathrm{~mm}$.
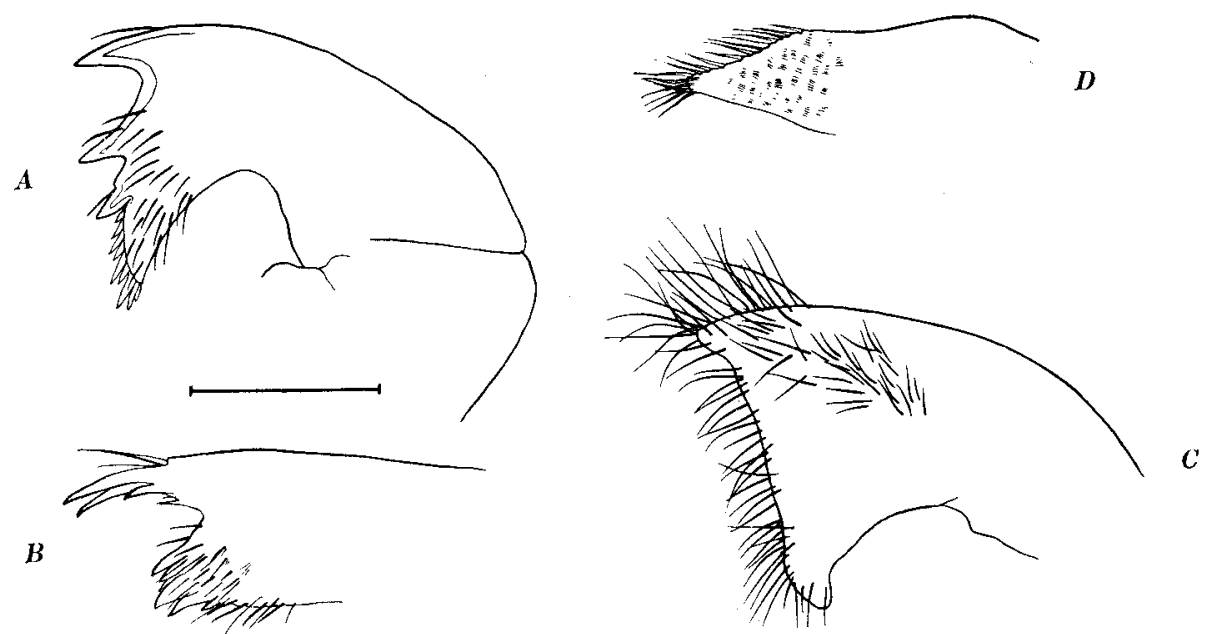

Fig. 16. Kochlorine habei, female. Mouth parts of specimen from Bursa bufo. $A$-mandible ; $B$-first maxilla ; $C$-second maxilla ; $D$-palp. Scale $0.1 \mathrm{~mm}$.

all shared the typical notch and the two secondary spines, although the Bursa specimens had additional even smaller spines on the inner (or lower) set.

The second maxillae were all typical of the order. 
In the dissection of a Charonia specimen the palp came off with the labrum (fig. 17A). This points up a recurring difficulty of determining whether this is truly a mandibular palp.

A specimen from Bursa showed higher bases on the bristles of the mouth cirrus than was typical for the Kelletia specimens (fig. 15).

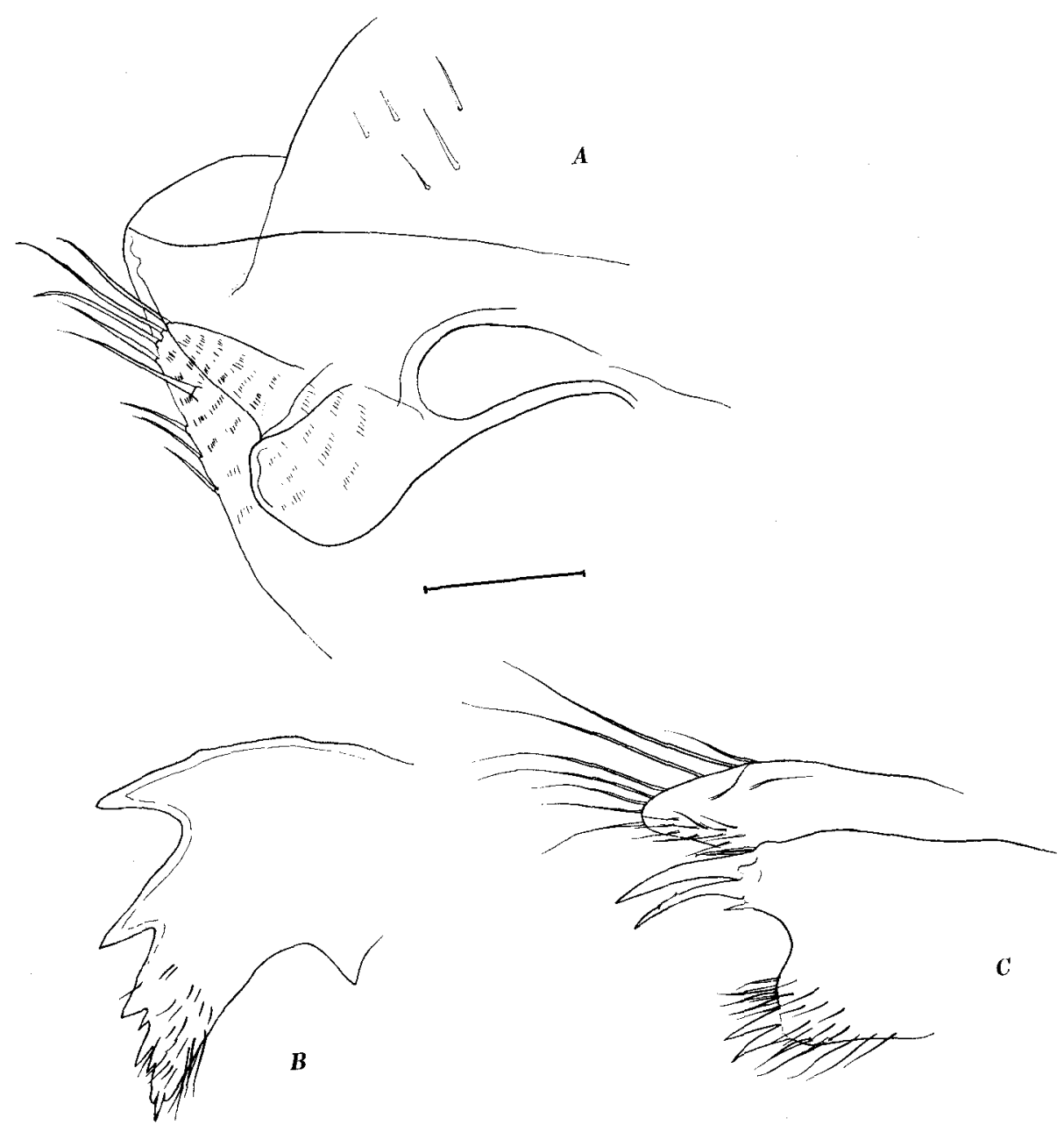

Fig. 17. Kochlorine habei, female. Mouth parts of specimen from Charonia sauliae. $A$-labrum and palp ; $B$-mandible ; $C$-first maxilla and palp. Scale $0.1 \mathrm{~mm}$.

The rest of the structures, including the highly variable apertural margin, are within the variation seen in the Kelletia specimens (figs. 13 and 14).

Affinities:

If the two hooks were posterior instead of near the anterior end, and the teeth were all spiny instead of some being bifurcated, Kochlorine habei would 
resemble a small specimen of $K$. bihamata NolL (1883). Noll's description of $K$. hamata (1875) indicates that he was properly aware of the animal's orientation, so this is probably not an error on his part, and so the proposed new species is apparently separable from $K$. bihamata. No illustrations exist for K. bihamata. This species represents the third in the genus.

This work was conducted at the Seto Marine

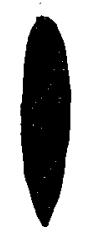

Fig. 18. Kochlorine habei, female. Aperture of burrow ("slit") in shell of Charonia sauliae. $1.1 \times 0.23 \mathrm{~mm}$.

Biological Laboratory through the generosity of Professor Huzio UTINomi and his staff, to whom the author and his wife will remain grateful. This investigation was supported in part by Public Health Service Research Grant GM 09953-02, from the National Institutes of Health, and in part by a sabbatical leave from San Francisco State College. My wife, Jean gave valuable assistance with the manuscript.

\section{REFERENCES}

Aurivillius, C. W. S. 1894. Studien über Cirripeden. Svensk. Vet. Akad. Handl., Ser. 4, Bd. 26, No. 7, pp. 1-107, pls. 1-8.

BARNARD, K. H. 1924. Contributions to the crustacean fauna of South Africa. Ann. S. Afr. Mus., Vol. 20, Pt. 1, pp. 1-103.

Berndt, W. 1907. Utber das System der Acrothoracica. Arch. Naturg., Jahrg. 73, Bd. 1, pp. 287289.

Calman, W. T. 1909. In: Lankester's A Treatise on Zoology, Pt. 7, Fasc. 3, Crustacea, pp. 106-142, A. \& C. Black, London.

Gruvel, A. 1905. Monographie des Cirrhipedes ou Thécostraces. 472 pp. Masson et Cie. Paris. KRÜGER, P. 1940. Cirripedia und Ascothoracida. In: BRonN's Klassen und Ordnungen d. Tier. reichs, Bd. 5, Abt. 1, Buch 3, Teil III, pp. 1-560.

NolL, F. C. 1875, Kochlorine hamata N., ein bohrendes Cirriped. Zeitshr. wiss. Zool., Bd. 25, Ht. 1, pp. 114-128., pl. 6.

1883. Zur Verbreitung von Kochlorine N. Zool. Anz., Bd. 6, pp. 471-472.

Tomlinson, Jack T. and William A. Newman. 1960. Lithoglyptes spinatus, a burrowing barnacle from Jamaica. Proc. U. S. National Mus., Vol. 112, No. 3445, pp. 517-526.

UTINOMI, H. 1950a. On another form of Acrothoracica, newly found from Formosa. Mem. Coll. Sci., Kyoto Imp. Univ., Ser. B, Vol. 19, No. 3, pp. 91-96 (pp. 1-6 in reprint).

1950b. General account of Acrothoracica. In : NAKAMURA's Some problems of modern biology, pp. 428-461. Zôsindô, Osaka.

- 1960. Studies on the Cirripedia Acrothoracica. II. Internal anatomy of the female of Berndtia purpurea Utinomi. Publ. Seto Mar. Biol. Lab., Vol. 8, No. 2, pp. 223--279, pls. 3133.

1961. Idem. III. Development of the female and male of Berndtia purpurea Utinomi. Ibid., Vol. 9, No. 2, pp. 413-446.

1963. Idem. IV. Morphology of the female of Balanodytes taiwanus Utinomi. Ibid.,

Vol. 11, No. 1, pp. 57-73, pl. 1. 